\title{
Hot topic: Investigating the risk of violative meat residues in bob veal calves fed colostrum from cows treated at dry-off with cephapirin benzathine
}

\author{
K. Hausler, ${ }^{*}$ S. M. Godden, ${ }^{* 1}$ M. J. Schneider,† A. R. Lightfield,† M. Bulthaus,‡ and D. Haines§ \\ *Department of Veterinary Population Medicine, University of Minnesota, St. Paul 55108 \\ †US Department of Agriculture-Agricultural Research Service, Eastern Regional Research Center, Wyndmoor, PA 19038 \\ łDQCI Services, Mounds View, MN 55112 \\ §Department of Veterinary Microbiology, University of Saskatchewan, Saskatoon, SK S7N 5B4, Canada
}

\section{ABSTRACT}

The objective was to conduct a study to investigate if violative meat residues are detected in very young bob veal calves that are fed first-milking colostrum harvested from cows that were dry treated, on-label, with cephapirin benzathine. First-milking colostrum was collected from cows that were given intramammary treatment at dry off, on-label, with cephapirin benzathine (ToMORROW, Boehringer Ingelheim Vetmedica Inc., St. Joseph, MO). Newborn bull calves meeting study inclusion criteria were removed from their dams shortly after birth and before suckling, and assigned to 1 of 2 trials. For the first trial, 6 treated calves were fed $3.8 \mathrm{~L}$ of fresh maternal colostrum and 1 control calf was fed 1.5 doses of a plasma-derived colostrum replacer (Secure Calf Colostrum Replacer, VitaPlus Inc., Madison, WI) within $1 \mathrm{~h}$ after birth. For the second trial, 5 treated calves were fed $3.8 \mathrm{~L}$ of fresh maternal colostrum and 1 control calf was fed 1.5 doses of Secure Calf Colostrum Replacer within $1 \mathrm{~h}$ after birth. All calves were humanely euthanized at $24 \mathrm{~h}$ (trial 1) or $48 \mathrm{~h}$ (trial 2) of age, and tissues were harvested for antimicrobial residue testing. Samples of maternal colostrum and colostrum replacer were also submitted for antimicrobial residue testing. Kidneys collected from all study calves tested negative for cephapirin benzathine residues when using both the KIS assay (Charm Sciences, Lawrence, MA) and liquid chromatographytandem mass spectrometry analysis. The potential transfer of cephapirin from cows treated on-label at dry off to calves via colostrum may not be a significant source of cephapirin residues in veal tissues.

Key words: colostrum, veal calf, antibiotic residue

Received June 29, 2012.

Accepted January 8, 2013.

${ }^{1}$ Corresponding author: godde $002 @ u m n . e d u$

\section{INTRODUCTION}

Food animal producers, veterinarians, and consumers are increasingly concerned about judicious drug use on dairy farms as it relates to the risk of drug residues in meat and milk, a residue being defined as a drug at a concentration above the legal tolerance. As a consequence of these mounting concerns, the US Food and Drug Administration (FDA) has recently initiated a milk-residue survey to investigate if there is a correlation between drug residues in cull cow carcasses and drug residues in milk (Dairy Herd Network, 2012). Other sectors of the food animal industry will also be under increased scrutiny. Dairy producers and veterinarians are responsible for minimizing the risk of creating violative residues in meat or milk leaving dairy premises. One frequently overlooked source of meat leaving dairies is bob veal; that is, calves slaughtered $<3$ wk of age or up to $150 \mathrm{lbs}$ (USDA, 2008). Bob veal is currently described by the US Department of Agriculture Food Safety and Inspection Service (USDAFSIS) as the production class having the highest risk for violative meat residues. As an example, the 2008 FSIS Scheduled Sampling Plan (USDA-FSIS, 2008) reported that, of 818 samples tested from bob veal calves, $2.4 \%$ of samples yielded a nonviolative positive result and $0.24 \%$ of samples yielded a violative test result. By comparison, only $0.07 \%$ of 1,405 samples from beef cows yielded a violative test result (USDA-FSIS, 2008). Among inspector-generated samples in 2008, the violation rate was higher: $0.89 \%$ for bob veal (USDA-FSIS, 2008). The USDA Inspector General has reported that over $90 \%$ of the violations reported in the FSIS Residue Violation Information System in 2008 were found in cull dairy cows and bob veal, whereas only $4 \%$ of violations were found in beef cattle (USDA-FSIS, 2010a). The top violative compounds reported for bob veal include neomycin, flunixin, and penicillin (USDA-FSIS, 2011). Dairy producers who frequently sell day-old bull calves to veal producers do not want antibiotic use practices on the source dairy (site of birth) to contribute to the problem of violative residues in bob veal. 
One conceivable source of antibiotic exposure to bob veal calves might be through colostrum from cows treated with intramammary antibiotics at dry off. With the exception of Spectramast DC (Pfizer Animal Health Inc., New York, NY), which has no preslaughter withdrawal period in calves following colostrum consumption, little is known about the magnitude or likelihood of this risk for cows treated with other dry cow intramammary antibiotic products. The ToMORROW product (cephapirin benzathine, Boehringer Ingelheim Vetmedica Inc., St. Joseph, MO) is for intramammary infusion at the time of dry off. Each 10-mL disposable syringe contains $300 \mathrm{mg}$ of cephapirin activity in a stable peanut oil gel. Milk from treated cows must not be used for food within $30 \mathrm{~d}$ after dry off or during the first 72 $\mathrm{h}$ after calving. Any animal infused with this product must not be slaughtered for food until $42 \mathrm{~d}$ after the latest infusion. The package insert for ToMORROW does not provide any recommended preslaughter withdrawal period for neonatal calves that have consumed colostrum from cows treated with the product. Although cephapirin has not been listed among the top violative compounds in bob veal, it is possible that antimicrobial agents in colostrum or milk fed to calves could result in residues. As an example, Musser et al. (2001) reported that calves fed milk spiked with amoxicillin or penicillin $\mathrm{G}$ could have violative residues if slaughtered within 24 $\mathrm{h}$ after feeding. The study objective was to investigate if violative meat residues are detected in very young bob veal calves that are fed colostrum from cows that were dry treated, on-label, with cephapirin benzathine.

\section{MATERIALS AND METHODS}

\section{Study Site and Dry Cow Management}

This project was approved by the University of Minnesota Institutional Animal Care and Use Committee. The study was completed on a 400-cow transition cow facility (Emerald Dairy II, Emerald, WI). This is a freestall facility housing approximately 300 close-up dry cows and heifers in addition to approximately 100 fresh cows between 1 and 21 DIM. The dry-off procedure routinely used by the farm was as follows: Cows due to dry off enter the parlor and are milked for the last time. Following milking, farm staff aseptically infuse one tube of cephapirin benzathine (ToMORROW, Boehringer Ingelheim Vetmedica Inc.) into each quarter and massage the gland. Next, each quarter is aseptically infused with an internal teat sealant (OrbeSeal, Pfizer Animal Health), and then post-dipped with an iodinebased teat dip. Following dry off, cows are housed in a group pen with access to freestalls bedded with manure solids for the duration of the dry period. Farm staff routinely observe the close-up freestall pens hourly and cows are moved into individual straw-bedded maternity stalls when calving is imminent. Following calving, the dam is allowed to lick the calf for 20 to $30 \mathrm{~min}$, but the calf is routinely removed from the dam between 30 and $60 \mathrm{~min}$ and before suckling can occur. Colostrum is harvested within 30 to 90 min after calving, and calves are hand-fed one 3.8-L feeding of fresh colostrum from the dam using an esophageal tube feeder.

\section{Colostrum Collection and Sampling}

First-milking colostrum was collected from cows (lactation 2 or greater) that had been previously treated at dry off with cephapirin benzathine. The labeled minimum 30-d dry off period had to be satisfied before calving for a cow's colostrum or her calf to be eligible for enrollment into the study. Additionally, eligible colostrum must have come from cows that were not treated with any other antibiotics or antiinflammatory agents during the dry period. Also, eligible cows must produce at least $4 \mathrm{~L}$ of colostrum at first milking. After harvesting into a clean, previously sanitized, bucket milker, the fresh colostrum was then transferred into a clean, sanitized container and labeled (cow ID, date collected, volume collected) in preparation for feeding to the calf. Immediately before feeding, the colostrum was thoroughly mixed and duplicate 20 -mL samples of colostrum were collected into sterile vials and frozen on farm at $-20^{\circ} \mathrm{C}$ for later testing for IgG concentrations and antimicrobial residues.

\section{Calf Enrollment and Sampling}

Newborn Holstein bull calves from observed calvings were eligible for enrollment providing they met the following inclusion criteria: (1) birth weight $\geq 31.8 \mathrm{~kg}$ (70 lbs), (2) singleton, and (3) dystocia score of 1 to 3 on a scale of 1 to 5 ( $1=$ unassisted, $2=$ easy pull, $3=$ moderate pull, $4=$ hard pull, $5=\mathrm{C}$-section). Calves were removed from the maternity pen within 30 to 60 min after calving and before the calf could suckle the dam. A $10-\mathrm{mL}$ venous blood sample was collected from the jugular vein before colostrum feeding. The calf was then randomly assigned to a trial (trial 1 or trial 2).

Trial 1: 24-Hour Harvest Group. Calves in this trial were designated to have tissues harvested at $24 \mathrm{~h}$ of age. Six calves were assigned to the treated group to be fed fresh maternal colostrum (MC) previously collected from their dam. A total of $3.8 \mathrm{~L}$ of warmed fresh colostrum from the dam was then administered to the calf, within $1 \mathrm{~h}$ of birth, using an esophageal tube feeder. One calf was randomly assigned to the control group, and was fed 1.5 doses of a commercially avail- 
able colostrum replacer (CR) (Secure Calf Colostrum Replacer, VitaPlus Inc., Madison, WI) mixed according to label directions, which would deliver a total of approximately $188 \mathrm{~g}$ of plasma-derived globulin protein to the calf. Two 20-mL samples of the mixed CR solution were collected and frozen, and the control calf was fed within $1 \mathrm{~h}$ of birth using an esophageal tube feeder. This calf was considered the control animal because the plasma-derived CR would not contain any antimicrobial agents. For all enrolled animals, calf ID, dam ID, birth date and time, birth weight, dystocia score, trial assigned (1 or 2$)$, colostrum type fed (MC or CR), and colostrum feeding time was recorded.

Trial 2: 48-Hour Harvest Group. The same enrollment procedure as described for trial 1 was used to enroll 6 calves ( 5 treated calves and 1 control calf), which were to be euthanized and tissues harvested at $48 \mathrm{~h}$ of age.

After the first colostrum feeding, study calves from both trials were housed in individual straw-bedded pens with solid dividers between calves. A milk protein-based milk replacer was fed using a nipple bottle at $1.9 \mathrm{~L}$ per feeding twice daily, until time of euthanasia and tissue harvest (Amplifier Max Calf Growth Formula, Land O'Lakes Animal Milk Products Co., Shoreview, MN). The milk replacer formula was selected so that it would not serve as an inadvertent source of antimicrobial exposure; this formula contains difubenzuron (ClariFly) at $12 \mathrm{mg} / \mathrm{kg}$ and lasalocid at $79.4 \mathrm{mg} / \mathrm{kg}$, but is certified by the manufacturer not to contain antimicrobial agents that would produce a drug residue. Calves had ad libitum access to water. At $24 \mathrm{~h}$ of age, a second 10$\mathrm{mL}$ venous blood sample was collected from the jugular vein for later serum IgG testing to verify that passive transfer of colostral IgG had occurred.

Blood samples collected at 0 (prefeeding) and $24 \mathrm{~h}$ of age were refrigerated overnight and centrifuged at $13,000 \times \mathrm{g}$, for $10 \mathrm{~min}$ at $20^{\circ} \mathrm{C}$, and the serum was collected. Duplicate 1-mL serum samples were collected into sterile tubes, labeled with calf ID, sample type $(0$ or $24 \mathrm{~h})$, date, and time, and frozen on farm at $-20^{\circ} \mathrm{C}$. Upon completion of the study, all frozen serum and colostrum samples were transported on ice to the University of Minnesota (St. Paul).

\section{Tissue Harvest Procedures}

Calves enrolled in trials 1 and 2 were humanely euthanized at 24 and $48 \mathrm{~h}$, respectively. Immediately following euthanasia, the study technician, wearing sterile gloves, collected both kidneys and the diaphragm from each calf. These tissues were placed into separate ziplock bags labeled with calf ID, time, and date. The tissues were immediately frozen at $-20^{\circ} \mathrm{C}$ on the farm for up to $2 \mathrm{wk}$, until a number of tissue samples could be transported on ice to the University of Minnesota (St. Paul). From there, they were shipped on dry ice to the USDA Agricultural Research Service laboratory (Eastern Regional Research Center, Wyndmoor, PA), where they were stored at $-80^{\circ} \mathrm{C}$ before being tested for tissue residues.

\section{Sample Testing}

Serum and Colostrum IgG Testing. Frozen serum samples collected at 0 and $24 \mathrm{~h}$ of age and frozen MC and CR samples were submitted, on ice, to Prairie Diagnostic Services Laboratory (Saskatoon, SK, Canada), where they were thawed and tested for total IgG concentration $(\mathrm{mg} / \mathrm{mL})$ by means of radial immunodiffusion, as described by Chelack et al. (1993).

Colostrum Antimicrobial Residue Testing. Frozen MC and CR samples were transported, on ice, to DQCI Services Laboratory (Mounds View, MN) where they were thawed and tested using the Charm II System as a screening test for the presence of antimicrobial residues (Charm Sciences Inc., Lawrence, MA). The limit of detection of the Charm II Quantitative assay for cephapirin in milk is $4.1 \mu \mathrm{g} / \mathrm{kg}$. The Charm II System is not analytically specific for the antimicrobial cephapirin, and this assay has not been validated for use with colostrum; therefore, a subset of samples with unconfirmed positive results using the Charm II assay underwent additional confirmatory testing using HPLC to confirm the presence of antimicrobials, and specifically to confirm the presence of cephapirin residues (HPLC receptogram assay using HPLC from the method of Zomer et al., 1995). All colostrum samples were analyzed by HPLC on the same day. The HPLC method is used to confirm and identify inhibitors in samples that have already been identified as positive. For $\beta$-lactams, HPLC separates the 6 common or approved $\beta$-lactams-penicillin, ampicillin, amoxicillin, cloxacillin, cephapirin, and ceftiofur -into distinct fractions, and each is collected from the column separately. The final step in the testing uses the fraction corresponding to each of these $6 \beta$-lactams as a sample for the Charm II Quantitative assay. Samples that were positive on this assay were then confirmed to be positive for the respective fraction.

Tissue Residue Testing. For tissue residue testing, kidney inhibition swab (KIS) kits, including test swab devices and negative control tablets, were purchased from Charm Sciences. Penicillin G (100\%) and cephapirin sodium (93\%) were from United States Pharmacopeia and desacetylcephapirin was from the USDA-FSIS. Hexane and acetonitrile were obtained from Fisher (Fairlawn, NJ). All aqueous solutions were prepared 
with deionized water from a Barnstead (Dubuque, IA) E-pure system. Stock solutions of cephapirin $(1,078$ $\mathrm{mg} / \mathrm{L})$ and desacetylcephapirin $(560 \mathrm{mg} / \mathrm{L})$ were prepared in water, as was a $5 \mathrm{ppm}$ composite solution to be used for fortification. The KIS assay was performed as described in the FSIS protocol (USDA-FSIS, 2010b), using both positive $(50 \mu \mathrm{g} / \mathrm{kg}$ of penicillin $\mathrm{G})$ and negative (negative control tablet) controls.

Extraction of Tissue Samples. Tissue extraction for liquid chromatography-tandem MS (LC-MS/MS) was performed as described by Lehotay et al. (2012) and Geis-Asteggiante et al. (2012). One frozen kidney was selected for testing for each calf (the remaining kidney plus diaphragm were kept for future additional testing, if necessary). Kidney samples ( $2.0 \mathrm{~g})$ were weighed into 50-mL disposable centrifuge tubes (2 samples/kidney) and stored at $-20^{\circ} \mathrm{C}$ until analysis. After thawing $(1 \mathrm{~h})$, $80 \%$ acetonitrile in water $(10 \mathrm{~mL})$ was added, and the tubes were placed on a platform shaker (Wilmad/GlasCol, Terre Haute, IN) for $5 \mathrm{~min}$. Tubes were centrifuged $(3,716 \times g, 5 \mathrm{~min})$ and the extract decanted into a 50 $\mathrm{mL}$ disposable centrifuge tube containing $0.5 \mathrm{~g}$ of C-18 sorbent (J.T. Baker, Phillipsburg, NJ). Hexane $(10 \mathrm{~mL})$ saturated with acetonitrile was added, and tubes were vortexed on the platform shaker $(1 \mathrm{~min})$ and then centrifuged $(3,716 \times g, 5 \mathrm{~min})$. Hexane was then aspirated to waste, and a $5-\mathrm{mL}$ aliquot of the acetonitrile-water supernatant was evaporated to $<0.5 \mathrm{~mL}$ under nitrogen at $45^{\circ} \mathrm{C}$ on a TurboVap LV (Zymark, Hopkinton, MA) and diluted with water to $1.0 \mathrm{~mL}$. Samples were then transferred to $0.2-\mu \mathrm{m}$, polyvinyl difluoride miniUniprep filter vials (Whatman, Florham Park, NJ).

$\boldsymbol{L} \boldsymbol{C}-\boldsymbol{M S} \boldsymbol{S} \boldsymbol{M}$ Analysis. Analysis of samples was done using an Acquity UPLC-TQD system, with MassLynx 4.1 software (Waters, Milford, MA). Liquid chromatography used a Kinetix $2.6 \mu \mathrm{m}$ C-18 column, $50 \mathrm{~mm} \times 3.00 \mathrm{~mm}$ i.d. (Phenomenex, Torrance, CA) at $40^{\circ} \mathrm{C}$. Analytes were eluted with a flow rate of 0.5 $\mathrm{mL} / \mathrm{min}$ and a gradient composed of solvent A $(2 \%$ acetonitrile in water with $0.1 \%$ formic acid) and solvent $\mathrm{B}$ (acetonitrile with $0.1 \%$ formic acid) as follows: 100\% A (0 to $5 \mathrm{~min}$ ), $92 \%$ A (10 to $12 \mathrm{~min}$ ). The mass spectrometer was operated in positive electrospray mode, and the following 3 transitions were monitored for cephapirin $(m / z 424.22$ to $292.05,151.9,111.07)$ and desacetylcephapirin $(\mathrm{m} / z 382.08$ to $111.28,124.17$, 152.02). The cone voltage for cephapirin was set at 24 $\mathrm{V}$, with collision energies of 16,24 , and $54 \mathrm{eV}$ for the 3 transitions, respectively. Desacetylcephapirin used a cone voltage of $32 \mathrm{~V}$, with collision energies of 48,48 , and $28 \mathrm{eV}$, respectively. All other tuning parameters were optimized automatically using Intellistart software (Waters). Matrix-matched calibration curves $(0$,
$5,10,25,50,100,150,200 \mathrm{ng} / \mathrm{g})$ were used to estimate concentrations of test samples.

Duplicate samples of all tissues examined by the KIS test were analyzed to confirm the results. All samples were analyzed in a single day. Quality assurance steps included the following: (1) in the injection sequence, the incurred samples were bracketed by matrix-matched standards; (2) data interpretation was performed to determine the linearity of the calibration curve over a dynamic range of 5 to $200 \mathrm{ng} / \mathrm{mL}$ for reagent only and matrix-matched standards; and (3) data interpretation was performed to determine reproducibility of ion ratios $(2 / 1,3 / 1,3 / 2)$ for reagent only, and matrix-matched standard results had a residual standard deviation of $<10 \%$ for all 3 ratios. A comparison between reagent only and matrix-matched standards were within acceptable standard deviations of each other.

\section{Data Analysis}

As the study tested a limited number of colostrum and tissue samples, formal statistical tests of difference were not completed. However, descriptive statistics were generated to describe, for each trial (24- and 48-h harvest) and treatment group (MC, CR), dam characteristics (parity, days dry, dystocia score, time to colostrum harvest, volume of colostrum produced), colostrum characteristics (IgG, $\mathrm{mg} / \mathrm{mL}$ ), and calf characteristics (birth weight, time to colostrum feeding, mass of IgG fed, 0- and 24-h serum IgG, mg/mL). Antimicrobial residue test results for colostrum and tissue samples were described for each trial and treatment group.

\section{RESULTS AND DISCUSSION}

All on-farm procedures involving colostrum harvest, calf enrollment, and tissue harvest procedures were completed in May and June 2011 by the study technician. Two calves enrolled in trial 1, 1 in the treated group and 1 in the control group, died from undetermined causes before euthanasia, and so were omitted from the study and replaced with 2 new calves. Upon completion of the study, colostrum and tissue samples were collected from 7 calves for trial 1 (6 treated, 1 control) and 6 calves for trial 2 (5 treated, 1 control), respectively.

\section{Cow, Colostrum, and Calf Characteristics}

Although formal statistical tests of differences were not applied, characteristics of cows, calves, and colostrum samples were numerically similar for trials 1 and 2 , and between treated and control groups (Table 1). 
For all dams enrolled, the mean (SD) parity, days dry, dystocia score, time to colostrum harvest, and volume of colostrum produced were 2.5 (0.8) lactations, 47.3 (5.5) days dry, $1.8(0.6)$ dystocia score, 37.1 (8.0) min from calving to colostrum harvest, and $6.0(1.2) \mathrm{L}$ of colostrum produced, respectively. The overall mean (SD) colostrum IgG concentration was 69.9 (24.4) $\mathrm{mg} / \mathrm{mL}$. For all calves enrolled, the mean (SD) birth weight, time to colostrum feeding, mass of IgG fed, and 0 - and 24-h serum IgG concentrations were 50.8 (5.5) $\mathrm{kg}, 49$ (8.5) min at first feeding, 265.4 (92.7) g of IgG consumed, $0.2(0.1) \mathrm{mg} / \mathrm{mL}$ IgG prefeeding, and 22.1 (10.8) $\mathrm{mg} / \mathrm{mL}$ IgG at $24 \mathrm{~h}$, respectively. Low precolostral serum IgG concentrations indicated that no study calves consumed colostrum before enrollment. Higher 24-h serum IgG concentrations indicated that all study calves were fed colostrum.

All calves enrolled had a dystocia score ranging from 1 to 3 on a scale of 1 to $5(1=$ unassisted, $2=$ easy pull, $3=$ moderate pull, $4=$ hard pull, $5=\mathrm{C}$-section). Calves with moderate to severe dystocia scores were omitted from enrollment because of concerns that they might have impaired absorption of colostral immunoglobulins and other colostral constituents. In fact, studies have reported equivocal results regarding the relationship between dystocia and passive transfer. Decreased colostral immunoglobulin absorption in the first $12 \mathrm{~h}$ has been reported in calves with postnatal respiratory aci- dosis, associated with prolonged parturition (Besser et al., 1990). Although hypoxic calves may have delayed IgG absorption initially (Tyler and Ramsey, 1991), studies have reported no difference in overall absorptive capacity between hypoxic and normoxic calves, and no difference in serum IgG concentrations by the time of gut closure (Tyler and Ramsey, 1991; Drewry et al., 1999). Weaver et al. (2000) suggested that an increased rate of failure of passive transfer seen in calves with metabolic or respiratory acidosis may be caused by a delay in the animal getting up to nurse, not by reduced absorptive capacity.

\section{Colostrum Residue Testing}

For both the 24-h and 48-h harvest trials, positive test results were attained for 2 of $2 \mathrm{CR}$ samples and for 10 of $11 \mathrm{MC}$ samples with preliminary (screening) testing using the Charm II System. Of the 12 samples that tested positive, both CR samples and 2 of the 10 MC samples were considered marginal (weak positive test). We considered these unconfirmed positive Charm II assay results to be suspicious, particularly because the $2 \mathrm{CR}$ samples, which were from a plasma-derived $\mathrm{CR}$ product and so should not contain any antimicrobials, showed weak positive results. To further investigate these unconfirmed positive results, the 5 colostrum samples with the strongest positive results on the Charm II

Table 1. Descriptive statistics [mean (SD; range)] for calves harvested at 24 or $48 \mathrm{~h}$ of age after receiving maternal colostrum or colostrum replacer

\begin{tabular}{|c|c|c|}
\hline Trial/variable & $\begin{array}{c}\text { Treated } \\
\text { (maternal colostrum) }\end{array}$ & $\begin{array}{c}\text { Control } \\
\text { (colostrum replacer) }\end{array}$ \\
\hline \multicolumn{3}{|l|}{ Trial 1: Tissues harvested at $24 \mathrm{~h}$} \\
\hline Number of calves enrolled & 6 & 1 \\
\hline Parity of dam & $2.5(0.8 ; 2-4)$ & 2.0 \\
\hline Days dry & $45.5(3.7 ; 39-50)$ & 47 \\
\hline Dystocia score (1 to 5 scale) & $2.0(0 ; 2-2)$ & 2 \\
\hline Birth weight $(\mathrm{kg})$ & $52.4(6.5 ; 45.8-64.4)$ & 42.6 \\
\hline Time to colostrum harvest (min) & $38.5(8.4 ; 30-48)$ & - \\
\hline Volume of colostrum produced (L) & $6.2(1.1 ; 4.7-8.0)$ & - \\
\hline Colostrum IgG $(\mathrm{mg} / \mathrm{mL})$ & $80.7(17.2 ; 66.2-113.8)$ & 50.0 \\
\hline Total mass of IgG fed (g) & $306.8(65.2 ; 251.6-432.4)$ & 190 \\
\hline Time to colostrum feeding ( $\min$ ) & $46.8(10.5 ; 35-58)$ & 55 \\
\hline 0-h serum IgG $(\mathrm{mg} / \mathrm{mL})$ & $0.3(0.1 ; 0.2-0.5)$ & 0.2 \\
\hline 24-h serum IgG $(\mathrm{mg} / \mathrm{mL})$ & $27.1(8.9 ; 15.9-43.3)$ & 15.2 \\
\hline \multicolumn{3}{|l|}{ Trial 2: Tissues harvested at $48 \mathrm{~h}$} \\
\hline Number of calves enrolled & 5 & 1 \\
\hline Parity of dam & $2.6(0.9 ; 2-4)$ & 2 \\
\hline Days dry & $47.8(7.0 ; 43-60)$ & 56 \\
\hline Dystocia score ( 1 to 5 scale) & $1.4(0.5 ; 1-2)$ & 3 \\
\hline Birth weight $(\mathrm{kg})$ & $49.4(2.8 ; 45.8-53.1)$ & 56.2 \\
\hline Time to colostrum harvest (min) & $35.4(8.0 ; 23-45)$ & - \\
\hline Volume of colostrum produced (L) & $5.7(1.5 ; 4.3-7.6)$ & - \\
\hline Colostrum IgG $(\mathrm{mg} / \mathrm{mL})$ & $64.5(31.9 ; 22.8-111.2)$ & 51.0 \\
\hline Total mass of IgG fed $(\mathrm{mg} / \mathrm{mL})$ & $245.3(121.2 ; 86.6-422.6)$ & 193.8 \\
\hline Time to colostrum feeding (min) & $50.2(7.8 ; 37-55)$ & 50 \\
\hline 0-h serum IgG $(\mathrm{mg} / \mathrm{mL})$ & $0.2(0 ; 0.2-0.2)$ & 0.2 \\
\hline 24-h serum $\operatorname{IgG}(\mathrm{mg} / \mathrm{mL})$ & $20.3(12.1 ; 8.0-39.5)$ & 8.1 \\
\hline
\end{tabular}


System screening test were submitted for confirmatory testing using HPLC (budget restrictions prevented us from submitting all $11 \mathrm{MC}$ samples for HPLC testing). The HPLC confirmatory testing yielded negative test results for antimicrobial residues in general and cephapirin specifically for all 5 colostrum samples tested.

One possible explanation for why the initial Charm II System screening test might yield an apparently falsepositive result for MC and plasma-derived CR samples may be that the assay was not developed and validated for use in colostrum. It was specifically developed and validated for normal commingled raw milk only; individual cow milk samples, colostrum, and abnormal raw milk (i.e., high fat milk) were not specifically validated. Another explanation for the unconfirmed positives on the Charm II assay is that this screening test may have greater analytic sensitivity $(90 / 95 \%$ confidence level is $4.1 \mathrm{ng} / \mathrm{g}$ ) than the confirmatory HPLC testing, allowing the Charm II assay to detect antimicrobial concentrations lower than the allowable legal limit in milk $(20 \mu \mathrm{g} / \mathrm{L})$.

\section{Tissue Residue Testing}

Antimicrobial agents were not detectable in any of the tissue samples tested by the KIS assay. The KIS assay, the standard test used routinely by the USDA in slaughterhouse antimicrobial residue screening programs, is capable of detecting cephapirin at a level of $100 \mathrm{ppb}$ in kidney tissue. Analysis by LC-MS/MS confirmed that none of the tissue samples tested contained either cephapirin or desacetylcephapirin at levels $\geq 5$ ng/g. The lowest calibrated level for the LC-MS/MS analysis was $5 \mathrm{ng} / \mathrm{g}$. The legal tolerance for cephapirin, according to the Code of Federal Regulations, is 0.1 ppm in uncooked edible tissues of dairy cattle and 0.02 ppm in milk (FDA, 2012). No legal tolerance limit has been established in veal calves, so any amount detected would have qualified as a violation.

A potential weakness in the design of this study was that we did not include positive control calves (i.e., calves intentionally administered an oral dose of cephapirin at birth). This choice was made because of budget constraints and ethical concerns and because we wanted to limit the number of calves enrolled and sacrificed. We do not consider the lack of positive control calves to jeopardize the validity or generalizability of study findings, given that tissue residue testing was conducted using the same published and validated techniques as used by FSIS laboratories in routine residue screening programs.

One potential limitation of the study methodology was that colostrum and calf tissue samples were frozen at $-20^{\circ} \mathrm{C}$ on the farm for a period between $2 \mathrm{~d}$ and $2 \mathrm{wk}$ before they were transported to the appropriate laboratory for residue testing. Had antimicrobial residues been present initially, it is unlikely that concentrations would have decreased below detectable limits during this storage period for all samples tested. However, we must acknowledge this possibility. In contrast, in surveillance programs conducted routinely by the USDA, fresh kidney samples are randomly selected from slaughtered animals, chilled, and submitted for rapid testing using the KIS test. Unfortunately, sampling logistics and cost limitations for the current study did not allow for immediate (daily) shipping of fresh tissue samples from Minnesota to the participating USDA lab in Pennsylvania.

In the event that tissues had tested positive, it would have been necessary to consider whether the antimicrobial in question were transferred from dam to calf in utero instead of through the colostrum. In a search of the literature, we were unable to locate a study describing trans-placental transmission of antimicrobial compounds in the bovine. Two veterinary clinical pharmacologists (M. Apley, Kansas State University, Manhattan; H. Coetzee, Iowa State University, Ames; personal communications) commented that although the possibility for this to occur exists, the potential is probably low, and that studies would be necessary to investigate this hypothesis.

No cephapirine benzathine residues were detected in tissue samples of 24- or 48-h-old calves that had been fed first-milking colostrum collected from cows that were dry treated, on-label, with cephapirin benzathine. Although these results suggest that giving cows intramammary treatment with cephapirin benzathine at the time dry off, on-label, is unlikely to result in a violative meat residue in bob veal calves, these results are restricted to a study population that included only cows that were treated on-label with cephapirin benzathine with dry period lengths between 39 and $60 \mathrm{~d}$. It would be useful to repeat the study to include other subpopulations of cattle, including cows treated on-label but with shorter dry periods (i.e., 30-39 d), cows that calve prematurely (i.e. dry period $<30 \mathrm{~d}$ ), cows that produce smaller volumes of first-milking colostrum (i.e., $<4 \mathrm{~L}$ ) and smaller calves $(<31.8 \mathrm{~kg}$ or $<70 \mathrm{lbs})$.

It must be stressed that, although the study did not detect cephapirin residues in first-milking colostrum when tested using HPLC, only a subset (50\%) of colostrum samples underwent confirmatory HPLC testing. The label for the cephapirin benzathine product (ToMORROW) used in this trial specifically states that milk from treated cows must not be used for food within $30 \mathrm{~d}$ after dry off or during the first $72 \mathrm{~h}$ after 
calving. Producers should be aware and carefully follow labels for product administration as well as meat and milk withholding times.

\section{CONCLUSION}

Potential transfer of cephapirin from cows treated on-label at dry off to calves via their colostrum may not be a significant source of cephapirin residues in veal tissues.

\section{ACKNOWLEDGMENTS}

This study was funded through the Boehringer Ingelheim Vetmedica Student Assistantship program, 2011. The authors thank the management and staff at Emerald Dairy II (Emerald, WI) for assisting with this study.

\section{REFERENCES}

Besser, T. E., O. Szenci, and C. C. Gay. 1990. Decreased colostral immunoglobulin absorption in calves with postnatal respiratory acidosis. J. Am. Vet. Med. Assoc. 196:1239-1243.

Chelack, B. J., P. S. Morley, and D. M. Haines. 1993. Evaluation of methods for dehydration of bovine colostrum for total replacement of normal colostrum in calves. Can. Vet. J. 34:407-412.

Dairy Herd Network. 2012. FDA begins milk-residue survey. Accessed Jun. 15, 2012. http://www.dairyherd.com/dairy-news/latest/ FDA-begins-milk-residue-survey--136947598.html.

Drewry, J. J., J. D. Quigley, and D. R. Geiser. 1999. Effect of high arterial carbon dioxide tension on efficiency of immunoglobulin $\mathrm{G}$ absorption in calves. Am. J. Vet. Res. 60:609-614.

FDA (Food and Drug Administration). 2012. 21CFR556: Tolerances for residues of new animal drugs in food. Accessed Oct. 2, 2012.
http://www.accessdata.fda.gov/scripts/cdrh/cfdocs/cfCFR/CFR Search.cfm?CFRPart $=556 \&$ showFR $=1$.

Geis-Asteggiante, L., S. J. Lehotay, A. R. Lightfield, T. Dutko, C. Ng, and L. Bluhm. 2012. Ruggedness testing and validation of a practical analytical method for $>100$ veterinary drug residues in bovine muscle by ultrahigh performance liquid chromatography-tandem mass spectrometry. J. Chromatogr. A 1258:43-54.

Lehotay, S. J., A. R. Lightfield, L. Geis-Asteggiante, M. J. Schneider, T. Dutko, C. Ng, L. Bluhm, and K. Mastovska. 2012. Development and validation of a streamlined method designed to detect residues of 62 veterinary drugs in bovine kidney using ultrahigh performance liquid chromatography-tandem mass spectrometry. Drug Test. Anal. 4(Suppl. 1):75-90.

Musser, J. M. B., K. L. Anderson, J. E. Rushing, and W. A. Moats. 2001. Potential for milk containing Penicillin G or Amoxicillin to cause residues in calves. J. Dairy Sci. 84:126-133.

Tyler, H., and H. Ramsey. 1991. Hypoxia in neonatal calves: Effect on intestinal transport of immunoglobulins. J. Dairy Sci. 74:19531956.

USDA. 2008. Office of Inspector General. Audit Report: Evaluation of FSIS Management Controls Over Pre-Slaughter Activities. Report No. 24601-0007-KC. Accessed Jun. 15, 2012. http://www.usda. gov/oig/webdocs/24601-07-KC.pdf.

USDA-FSIS. 2008. FSIS National Residue Program Data (Red Book). Accessed Jun. 15, 2012. http://www.fsis.usda.gov/PDF/2008_ Red_Book.pdf.

USDA-FSIS. 2010a. FSIS National Residue Program for Cattle. Audit Report 24601-08-KC. Accessed 06/15/2012. http://www.usda. gov/oig/webdocs/24601-08-KC.pdf.

USDA-FSIS. 2010b. KIS Test Instructions. Accessed Feb. 5, 2013. http://www.fsis.usda.gov/PDF/KIS_Booklet_0710.pdf.

USDA-FSIS. 2011. National Residue Program. United States Department of Agriculture Food Safety and Inspection Service. Accessed Sep. 4, 2012. http://www.lmaweb.com/alerts/files/AnimalDrug Residue/20110518FSISNationalResidueProgram.pdf.

Weaver, D. M., J. W. Tyler, D. C. VanMetre, D. E. Hostetler, and G. M. Barrington. 2000. Passive transfer of colostral immunoglobulins in calves. J. Vet. Intern. Med. 14:569-577.

Zomer, E., J. Quintana, S. Saul, and S. E. Charm. 1995. LC-receptogram: A method for identification and quantitation of beta-lactams in milk by liquid chromatography with microbial receptor assay. J. AOAC 78:1165-1172. 